\title{
Artículos
}

\section{Análisis de coyuntura económica* Primer semestre de 1998}

\author{
Departamento de Economía \\ Universidad Centroamericana "José Simeón Cañas"
}

\section{Resumen}

Este artículo muestra que la economía salvadoreña posee, desde el punto de vista macroeconómico, factores positivos, como un crecimiento económico moderado, una tasa de inflación baja en relación con otros países, una solvencia externa favorable, dado el alto nivel de reservas internacionales, etc., pero desde el punto de vista de bienestar económico de la población, los resultados no son compatibles con el comportamiento macroeconómico; en varios aspectos nuestra economía muestra señales de desigualdad: el estancamiento del sector agropecuario, la caída del poder de compra de los trabajadores que devengan el salario mínimo, una estructura impositiva regresiva, una distribución desigual del ingreso, etc. Esta situación obliga a pensar en políticas económicas que ayuden a combatir de manera más efectiva el fenómeno de la pobreza.

* Documento elaborado por Alvaro Trigueros (secciones 1, 2, 3, 5, y 6) y Francisco Lazo Marín (sección 4); ambos economistas y catedráticos del departamento de Economía de la Universidad Centroamericana "José Simeón Cañas". También se agradecen las sugerencias de Francisco Javier Ibisate S.J., Aquiles Montoya, Gerardo Olano y Rafael Pleitez. 


\section{Introducción}

Al primer semestre de 1998, la economía sigue un comportamiento similar al último año, con una situación macroeconómica relativamente aceptable que contrasta con varios problemas a nivel socioeconómico. La pobreza sigue siendo el principal problema sociocconómico y su incidencia es mucho mayor en las áreas rurales. El salario mínimo vigente ha disminuido su poder de compra en un 22 por ciento con respecto a diciembre de 1988. El moderado crecimiento económico de los últimos años no se ha traducido en mejoras sustanciales de los niveles de vida para la mayoría de salvadoreños.

En cuanto a la actividad económica agregada, la tendencia reciente muestra que el crecimiento agregado se mantendrá entre el 5 y el 4 por ciento, tal vez ligeramente superior al crecimiento del año pasado. Hay que considerar que este pronóstico se pucde ajustar hacia la baja debido a los altos niveles de delincuencia, la incertidumbre del período eleccionario -que retrasa algunas inversionesy los posibles efectos de la crisis asiática a mediano plazo. Sin embargo, el crecimiento de un 4 por ciento para la mayoría de la población no es muy alentador, según estimaciones, aún con el supuesto de una distribución equitativa de los ingresos, a dicha tasa, se necesitarían 35, años para duplicar los ingresos reales per cápita. Los sectores más dinámicos en este primer semestre, a nivel de producción y creación de empleo, han sido la industria manufacturera, la construcción y el sector financiero, micntras que el comercio y la agricultura han reducido su nivel de actividad económica en este primer semestre.

Respecto al nivel de precios, los primeros sietes meses del año muestran una tendencia ligeramente superior al año pasado. La presión en el nivel de inflación proviene principalmente de los rubros de alimentos y vivienda, pero es posible yue con las cosechas de los granos básicos estas presiones puedan disminuir un poco en lo que resla del año.

En todo caso, la inflación acumulada a lo largo de varios años, aunada a moderadas alzas en el salario mínimo, ha venido a signilicar un deterioro considerable en e! poder de compra de los trabajadores que devengan este salario. Hasta la fecha, el poder de compra del salario mínimo es un 22.5 por ciento más bajo que en diciembre de 1988. Al comparar el salario mínimo mensual con la canasta básica ampliada urbana se observa que aquél está muy lejos de satisfacer las necesidades materiales de los trabajadores, a pesar del incremento del 9 por ciento que se registró en el mes de mayo.

En el sistema financiero sobresalen tres tendencias. En primer lugar, se ha dado una recomposición en la cartera del público, quienes han reducido su tenencia en efectivo y depósitos de cuenta corriente, para aumentar sus depósitos en cuentas de ahorro y a plazo. Posiblemente esta tendencia es una respuesta rezagada a los altos niveles en la tasa de interés real en 1997, y a la recuperación de la confianza del público en el sistema bancario después del escándalo de Finsepro-Insepro. En segundo lugar, hay un aumento en la competencia en el sistema bancario. Con la entrada de nuevos bancos al sistema y de capital extranjero, los índices de concentración de depósitos muestran una leve tendencia a la baja. A la larga, este fenómeno puede favorecer a los usuarios del sistema bancario con mejores servicios. En tercer lugar, el crédito destinado a los diferentes sectores productivos se concentra en más del 42 por ciento para el comercio; mientras que el crédito destinado al sector agrícola representa aproximadamente un 11 por ciento. Con cl tiempo, este fenómeno pucde favorecer a los usuarios del sistema bancario con mejores servicios.

En cuanto a las finanzas públicas, para el primer semestre de 1998 se observa un deterioro en el ahorro corriente del Sector público no Financiero (SPNF), que disminuye en un 36 por ciento con respecto al mismo período del año anterior. La causa de este resultado negativo en las finanzas públicas parece provenir tanto del lado del gasto público, como de los ingresos. El gasto total del SPNF aumentó un 4 por ciento, mientras que los ingresos corrientes disminuyeron en 2.9 por ciento. La reducción de estos últimos se debe principalmente a la venta de empresas públicas, dentro del programa de privatización, de donde se destaca que las empresas vendidas generaban importantes ingresos para el sector público. Un aspecto positivo es el incremento del 7.5 por ciento de los ingresos tributarios con respecto al mismo período del año anterior. Sin embargo, la carga tributaria del país es baja; para 1997 fue de 10.8 por ciento con respecto al Producto Interno Bruto, una de las más bajas de América Latina y del mundo. Además, la estructura impositiva es bastante regresiva, 
ya que descansa principalmente en impuestos indirectos, como el IVA.

Finalmente, el sector externo sigue mostrando las tendencias positivas de los últimos años. Las exportaciones totales experimentaron un crecimiento del 7.4 por ciento con respecto al primer semestre del año anterior. Este comportamiento obedece a la dinámica de las exportaciones no tradicionales y de maquila. Sin embargo, la contribución de la maquila en la generación de divisas debe reconsiderarse hasta la fecha, ya que al comparar las exportaciones netas de maquila con las de café, éste último ha contribuido más a la generación de divisas y no la maquila. Sin embargo, esto se revertirá en la medida en que la maquila continúe su tendencia ascendente.

Asimismo se destaca que el déficit en la balanza comercial sigue disminuyendo en términos relativos con respecto a las exportaciones y las importaciones, lo que es una tendencia favorable para el país. Sin embargo, a junio de 1998 se registró un ligero incremento del déficit en términos absolutos, principalmente por la caída en los precios del café. Por otra parte, debido al fuerte flujo de divisas, un saldo positivo en la balanza de capitales, y a la política de tipo de cambio fijo, el nivel de reservas internacionales ha seguido aumentando con respecto al año anterior. Cabe resaltar que la acumulación de reservas, en los últimos años, ha sido posible en gran parte por las remesas familiares.

\section{Evolución de la producción y el empleo}

\subsection{EI IVAE}

El IVAE es un indicador del volumen de la actividad económica y, como tal, no pretende medir el total de producción sino, más bien, la tendencia de esta misma. En la Gráfica l' se establece una comparación entre la tasa de crecimiento del Producto Interno Bruto, a precios constantes de 1992, y la tasa de crecimiento del promedio móvil del IVAE a doce meses (IVAE12), para el mes de diciembre. Se observa que el IVAE12 está lejos de acertar en cuanto a la magnitud del crecimiento del Producto Interno Bruto, pues el IVAE12 muestra una mayor varianza, pero sí acierta en cuanto a la dirección del crecimiento; cuando el crecimiento IVAE1 2 sube, el crecimiento del PIB sube, y viceversa. Entrando en más detalle, el coeficiente de correlación entre las dos variables para los años 1991-1997 es de 0.76; al ser éste positivo y más o menos alto se puede concluir que, en conjunto, el movimiento de las variables coincide bastante bien, por lo que el IVAE permite capturar la dirección del movimiento del PIB y, en menor medida, la magnitud de estos movimientos.

\section{Gráfica 1}

Comparación de la variación anual del PIB y del IVAE 12 a diciembre

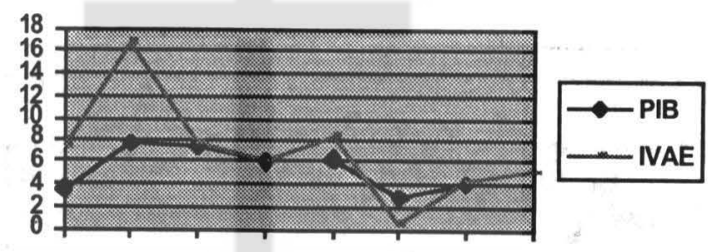

$1991199219931994199519961997 \quad 1998 / p$

Gráfica 2

IVAE promedio movil 12 meses (variaciones anuales)

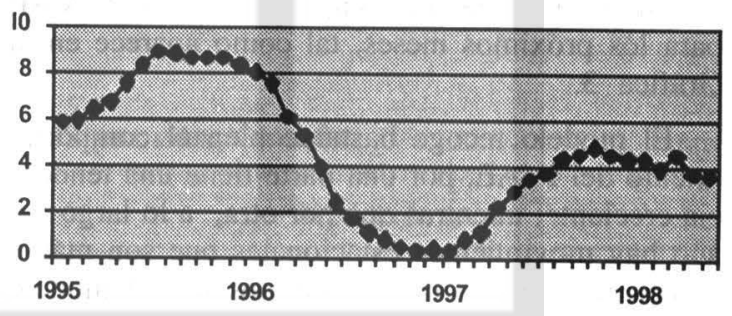

En la Gráfica 2 se plasma la variación anual del promedio móvil de doce meses del IVAE, y se observa que, en los meses de enero y febrero del corriente año, la tasa de crecimiento de la economía, aunque positiva, comenzaba a disminuir; pero en marzo se da un punto de inflexión donde la tasa de crecimiento se incrementó; luego nuevamente disminuyó un poco en los meses de abril y mayo. Estos movimientos son normales para esta época del año, pues justo después de las fiestas de Navidad y de fin de año y parte de las cosechas en la agricultura, la actividad productiva se reduce en los meses de enero y febrero por factores estacionales, pero en el mes de marzo se recupera leve-

1. A menos que se señale lo contrario, todos los gráficos se basan en información oficial. 
mente, y luego vuelve a caer un poco en abril y mayo, hasta que se recupera en junio. Para poder extraer más información de esta serie económica, se aplicó la metodología de Box-Jenkins de modelos ARIMA al IVAE. A partir de nuestras estimaciones econométricas hacemos un pronóstico del comportamiento del IVAE para los próximos doce meses del año.

\section{Gráfica 3 \\ Pronóstico del IVAE (logaritmo)}

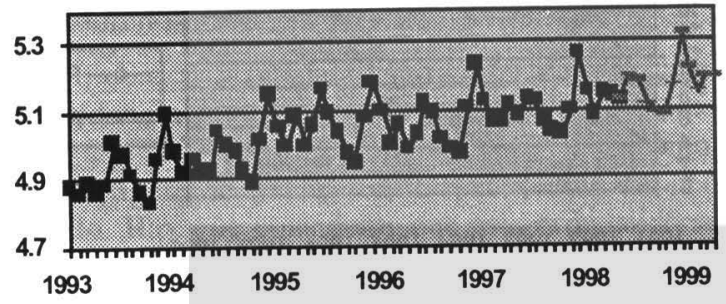

Partiendo de la información disponible hasta mayo de 1998 y del modelo estadístico estimado, podemos proyectar el comportamiento del IVAE para los próximos meses, tal como aparece en la Gráfica 3.

El modelo recoge bastante bien el comportamiento del IVAE, por una parte tiene una tendencia creciente; mientras que por otra, a lo largo del año hay movimientos estacionales que son más o menos regulares y son capturados por el modelo econométrico mencionado. En la Gráfica 3, la línea con cuadros representa las observaciones reales del IVAE (en logaritmos), y la línea que le sigue es el pronóstico que se hace para los siguientes doce meses utilizando el modelo estadístico econométrico mencionado. Esto nos permite adelantar, con cierto grado de cautela, que el IVAE seguirá una tendencia creciente, lo que es positivo, pues indica un aumento en los volúmenes de la actividad económica. Más concretamente, utilizando las proyecciones para 1998, se estima que el crecimiento del IVAE 12 para 1998 estará alrededor del 5.13 por ciento, un poco más alto que para 1997, lo que sugiere que el crecimiento del Producto Interno Bruto, en 1998, podría estar entre un 4 y 5 por ciento, respectivamente, siem- pre dentro de las proyecciones realizadas por el Banco Central de Reserva ${ }^{2}$ en el Programa Monetario y Financiero 1998. Sin embargo, hay que considerar la posibilidad de revisar estas proyecciones a la baja por el período electoral, que hace que se retrasen algunas inversiones por los posibles efectos negativos resultantes de las crisis asiática y rusa, y por la fuerte incidencia de la delincuencia en la actividad económica. Finalmente, las proyecciones muestran que en el tercer trimestre del año se experimentará una caída de la actividad económica, para volver a recuperarse nuevamente en el cuarto trimestre del año, todo ello como parte de los movimientos estacionales del IVAE.

Entrando en mayor detalle sobre la actividad de los diferentes sectores productivos; en el primer semestre de 1998, los sectores más dinámicos fueron la industria, la construcción y el sector financiero. El comercio y la agricultura, por su parte, experimentaron tasas negativas en sus promedios móviles aunque, para ésta última, el crecimiento negativo ha sido cada vez menor en los últimos dos meses de abril y mayo, para los cuales los datos están disponibles. En este sentido cabe resaltar que, en la década de los noventa, la agricultura es un sector que salió afectado negativamente por la política económica y que, al menos por este año, todavía no existen señales de recuperación.

Dada la magnitud del crecimiento económico y el comportamiento desigual en el crecimiento entre los diferentes sectores productivos, no se puede concluir de que exista un incremento general del bienestar económico. En primer lugar, tasas de crecimiento de alrededor del 2 por ciento en el ingreso per cápita implican que, de haber una distribución equitativa de los ingresos, las personas podrían esperar 35 años para duplicar sus ingresos. Pero la distribución del ingreso y la distribución del crecimiento no es equitativo en El Salvador.

\subsection{Empleo y desempleo}

Para tener una aproximación de la evolución del empleo en el sector formal de la economía a corto plazo, hay que remitirse a los datos del número de trabajadores del Instituto Salvadoreño del Seguro Social (ISSS) que cotizan por riesgo común. Esto deja fuera del análisis a todos los trabajadores del sector informal y a la gran mayoría de trabajadores

2 Ver "Programa Monetario y Financiero 1998". Boletín Económico, enero-febrero, 1998, No. 115. 
agrícolas que no cotizan al ISSS, para los cuáles es más difícil conseguir estadísticas a corto plazo.

\section{Gráfica 4}

Trabajadores cotizantes al ISSS (miles)

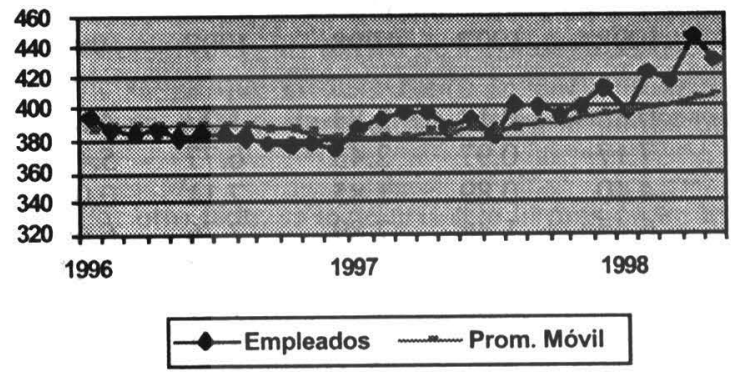

En los primeros cinco meses de 1998, el número de trabajadores cotizantes al ISSS se redujo en los meses de enero, marzo y mayo, pero -en promedio - para el mismo período en el año anterior, el número de empleados cotizantes al ISSS creció más este año. Al comparar la variación anual con respecto al año pasado se observa que en todos los cinco meses en cuestión, la tasa de crecimiento del empleo ha sido más dinámica en 1998, así como también la variación anual del promedio móvil para evaluar la tendencia de cotizantes al ISSS. Esto revela que los primeros meses de 1998 presentan una tendencia de crecimiento mayor que 1997, cuando los promedios móviles del total de empleados presentaban cifras negativas; en parte porque todavía acarreaban la desaceleración de 1996 (ver Cuadro 1 y Gráfica 4 ).

Desde un punto de vista sectorial, en el primer semestre de 1998, los sectores más dinámicos en la generación de empleos fueron la industria, la construcción y el sector financiero, lo que concuerda con los datos del IVAE, mientras que simultáneamente el comercio ha experimentado una disminución en su capacidad para generar empleo. Sin embargo, en el mes de mayo, el último para el cual hay información disponible hasta la fecha, todos los sectores experimentaron un rendimiento negativo en cuanto a generación de empleo.

\section{Cuadro 1}

Trabajadores cotizantes del ISSS por riesgo común

\begin{tabular}{|c|c|c|c|c|c|c|c|c|}
\hline \multirow[b]{3}{*}{ Mes } & \multicolumn{2}{|c|}{ Total } & \multicolumn{2}{|c|}{ Variación } & \multicolumn{4}{|c|}{ Variación anual } \\
\hline & \multirow[b]{2}{*}{1997} & \multirow[b]{2}{*}{1998} & \multicolumn{2}{|c|}{ Mensual } & \multicolumn{2}{|c|}{ Total } & \multicolumn{2}{|c|}{ Prom. móvil } \\
\hline & & & 1997 & 1998 & 1997 & 1998 & 1997 & 1998 \\
\hline Enero & 387,280 & 395,840 & 3.55 & -3.97 & -1.61 & 2.21 & -1.24 & 3.43 \\
\hline Febrero & 391,935 & 420,758 & 1.20 & 6.29 & 1.35 & 7.35 & -1.47 & 3.94 \\
\hline Marzo & 396,088 & 415,633 & 1.06 & -1.22 & 2.85 & 4.93 & -1.26 & 4.12 \\
\hline Abril & 395,728 & 445,145 & -0.09 & 7.10 & 2.24 & 12.49 & -1.26 & 4.99 \\
\hline Mayo & 387,332 & 430,660 & -2.12 & -3.25 & 1.29 & 11.19 & -1.07 & 5.82 \\
\hline Junio & 392,120 & & 1.24 & & 1.73 & & -0.86 & \\
\hline Julio & 384,076 & & -2.05 & & -0.26 & & -0.79 & \\
\hline Agosto & 400,670 & & 4.32 & & 4.89 & & -0.46 & \\
\hline Septiembre & 398,861 & & -0.45 & & 5.24 & & 0.44 & \\
\hline Octubre & 393,123 & & -1.44 & & 4.23 & & 1.08 & \\
\hline Noviembre & 399,732 & & 1.68 & & 5.46 & & 1.83 & \\
\hline Diciembre & 412,184 & & 3.12 & & 10.21 & & 3.10 & \\
\hline
\end{tabular}

Fuente: Instituto Salvadoreño del Seguro Social. 


\section{Cuadro 2 \\ Trabajadores cotizantes del ISSS \\ Por riesgo común: principales ramas por empleo formal (variación mensual)}

\begin{tabular}{|c|c|c|c|c|c|c|c|c|c|c|}
\hline \multirow[b]{2}{*}{ Mes } & \multicolumn{2}{|c|}{$\begin{array}{l}\text { Industria } \\
\text { Manufact. }\end{array}$} & \multicolumn{2}{|c|}{$\begin{array}{l}\text { Construcción } \\
\text { Pub. y Priv. }\end{array}$} & \multicolumn{2}{|c|}{ Comercio } & \multicolumn{2}{|c|}{ Financiero } & \multicolumn{2}{|c|}{$\begin{array}{l}\text { Servicios } \\
\text { Personales }\end{array}$} \\
\hline & 1997 & 1998 & 1997 & 1998 & 1997 & 1998 & 1997 & 1998 & 1997 & 1998 \\
\hline Enero & 5.61 & 2.84 & 2.61 & -3.34 & 2.69 & -0.85 & 0.18 & 3.84 & 1.27 & -4.81 \\
\hline Febrero & 0.77 & 6.90 & 5.75 & -6.39 & -0.98 & 7.17 & 0.97 & 2.43 & 6.77 & 5.41 \\
\hline Marzo & -0.86 & -2.10 & 1.36 & 5.27 & -0.99 & -4.40 & 0.89 & 1.85 & 7.11 & 0.06 \\
\hline Abril & 0.36 & 4.59 & 3.74 & 15.20 & -1.16 & 6.45 & 1.46 & 7.89 & -2.76 & 6.66 \\
\hline Mayo & -2.07 & -3.24 & 0.31 & -3.24 & -1.82 & -3.24 & -1.31 & -3.24 & -3.34 & -3.33 \\
\hline Junio & 1.03 & & 6.65 & & -0.74 & & 0.55 & & 1.97 & \\
\hline Julio & 1.21 & & -9.24 & & 0.66 & & -5.79 & & -2.01 & \\
\hline Agosto & 2.00 & & 2.41 & & 3.14 & & 7.75 & & 6.18 & \\
\hline Sept. & -0.87 & & -1.36 & & 1.11 & & -2.67 & & 0.84 & \\
\hline Octubre & -2.95 & & 2.03 & & -0.90 & & 2.40 & & -2.26 & \\
\hline Nov. & 3.67 & & -5.34 & & 0.64 & & 4.04 & & -0.61 & \\
\hline Dic. & 3.60 & & 2.84 & & 3.83 & & 0.46 & & 2.18 & \\
\hline
\end{tabular}

Fuente: Instituto Salvadoreño del Seguro Social.

\section{Evolución de los precios}

A nivel macroeconómico, los precios más importantes, como el Indice de Precios al Consumidor (IPC), muestran una inflación ligeramente superior al año anterior, pero siempre dentro de los límites establecidos en las metas del Banco Central de Reserva. Por el lado de las tasas de interés, tanto para préstamos como para depósitos, han tendido a la baja como producto de la reducción en la inflación, pero esta reducción ha sido lenta. En torno al salario mínimo, éste ha mostrado un continuo deterioro en su

general de precios de la canasta de consumo ha experimentado menores incrementos en los meses de enero, febrero y marzo, pero a partir del mes de abril se observa un incremento mayor. De acuerdo con los diferentes componentes de la canasta de consumo, la mayor presión en el alza de los precios proviene de alimentos y vivienda. Considerando que alimentos es el rubro que tiene mayor ponderación en el cálculo del índice general de precios, de este rubro proviene la mayor variación. En cuanto a la inflación punto a punto, es decir, la inflación ocurrida en los úlcapacidad de poder de compra, pero las autoridades no han realizado ninguna acción tendiente a su mejoría.

\subsection{Nivel general de precios}

Al analizar la inflación conviene comenzar por la inflación mensual. En el Cuadro 3 tenemos la inflación mensual acumulada para 1997 y los primeros sicte meses de 1998. En este año, el nivel timos doce meses a partir del mes correspondiente al año anterior, la inflación, a nivel general, ha sido menor en los primeros siete meses de 1998 que en los mismos meses de 1998 (ver Cuadro 3). Esıo no significa que la inflación pueda ser menor este año. En primer lugar, en los meses de enero a julio, la inflación punto a punto es más alta en 1997 porque todavía está arrastrando los mayores incrementos en los precios ocurridos en 1996, 
mientras que para 1998 se están arrastrando, para estos meses, los menores incrementos de precios de los meses agosto-diciembre de 1997. Lo mismo se puede observar para los rubros de alimentos, vestuario y misceláneos, pero no así para vivienda, que trae más inercia en el alza de los precios. De hecho, vivienda fue el rubro que mayor presión inflacionaria presentó durante 1997, en parte por el incremento de las tarifas de algunos de servicios públicos, ya que en este rubro se encuentran los gastos de agua y electricidad por parte de los hogares.

Por otro lado, se esperaría que la presión en los precios de los bienes alimenticios se redujera en los próximos meses al salir al mercado las cosechas de los granos básicos. También, con base en la inflación acumulada, parece que en este año habrá mayores niveles pero no un incremento tan drástico, por lo que es bastante probable que la inflación quede dentro de la meta propuesta por el Programa Monetario y Financiero 1998 del Banco Central de Reserva, principalmente porque las cosechas de los granos básicos en los próximos meses podrían reducir los precios de los bienes alimenticios.

En relación con la inflación de otros países centroamericanos, al primer semestre de 1998, El Salvador era el país con la tasa de inflación más baja, 2.8 por ciento; seguida por Guatemala, con una tasa de inflación igual a 7.9 por ciento; mientras que para Nicaragua y Costa Rica fue cerca del 11 por ciento, y la de Honduras alrededor del 14.8 por ciento. En la región centroamericana le favorece a El Salvador tener una inflación más baja, ya que así evita un mayor deterioro en los términos de intercambio comercial, y favorecen las exportaciones al área, tal como se describe en la sección de comercio exterior.

\section{Cuadro 3}

Indice de Precios al Consumidor Variación porcentual mensual acumulada base: diciembre $1992=100$

\begin{tabular}{|c|c|c|c|c|c|c|c|c|c|c|}
\hline \multirow[t]{2}{*}{ Mes } & \multicolumn{2}{|c|}{ General } & \multicolumn{2}{|c|}{ Alimentos } & \multicolumn{2}{|c|}{ Vivienda } & \multicolumn{2}{|c|}{ Vestuario } & \multicolumn{2}{|c|}{ Misceláneos } \\
\hline & 1997 & 1998 & 1997 & 1998 & 1997 & 1998 & 1997 & 1998 & 1997 & 1998 \\
\hline Enero & 1.7 & 1.2 & 2.1 & 1.0 & 1.0 & 2.1 & -0.1 & 0.2 & 2.0 & 1.1 \\
\hline Febrero & 2.2 & 1.5 & 2.8 & 1.3 & 1.3 & 2.7 & -0.1 & -0.1 & 2.3 & 1.1 \\
\hline Marzo & 2.4 & 1.9 & 3.0 & 2.3 & 1.7 & 2.6 & 0.1 & -0.4 & 2.4 & 1.1 \\
\hline Abril & 2.4 & 3.2 & 2.8 & 4.4 & 2.1 & 3.5 & 0.1 & -0.6 & 2.7 & 1.6 \\
\hline Mayo & 2.2 & 3.7 & 2.3 & 5.6 & 2.0 & 3.7 & 0.2 & -0.7 & 2.6 & 1.6 \\
\hline Junio & 2.6 & 3.8 & 3.0 & 5.8 & 2.3 & 4.0 & 0.0 & -0.7 & 2.7 & 1.4 \\
\hline Julio & 3.4 & 4.2 & 4.8 & 6.1 & 2.3 & 4.2 & 0.0 & -0.8 & 2.8 & 2.4 \\
\hline Agosto & 2.7 & & 2.9 & & 2.7 & & 0.0 & & 3.0 & \\
\hline Septiembre & 2.4 & & 1.8 & & 3.6 & & 0.0 & & 2.7 & \\
\hline Oclubre & 2.0 & & 1.1 & & 3.7 & & 0.0 & & 2.6 & \\
\hline Noviembre & 1.9 & & 0.2 & & 4.8 & & 0.0 & & 2.5 & \\
\hline Diciembre & 1.9 & & 0.4 & & 4.6 & & 0.0 & & 2.4 & \\
\hline
\end{tabular}

Fuente: Dirección General de Estadísticas y Censos.

3. Ver Banco Central de Reserva, "Estabilidad de precios se mantiene", Economía en Marcha, 13 de agosto de 1988. 


\section{Cuadro 4 \\ Indice de Precios al Consumidor \\ Variación porcentual anual (punto a punto) por grupos \\ base: diciembre 1992=100}

\begin{tabular}{|c|c|c|c|c|c|c|c|c|c|c|}
\hline \multirow[b]{2}{*}{ Mes } & \multicolumn{2}{|c|}{ General } & \multicolumn{2}{|c|}{ Alimentos } & \multicolumn{2}{|c|}{ Vivienda } & \multicolumn{2}{|c|}{ Vestuario } & \multicolumn{2}{|c|}{ Misceláneos } \\
\hline & 1997 & 1998 & 1997 & 1998 & 1997 & 1998 & 1997 & 1998 & 1997 & 1998 \\
\hline Enero & 7.5 & 1.5 & 11.7 & -0.7 & 5.7 & 5.9 & 1.1 & 0.3 & 4.9 & 1.5 \\
\hline Febrero & 7.8 & 1.3 & 12.1 & -1.1 & 5.9 & 6.1 & 0.7 & -0.1 & 5.3 & 1.1 \\
\hline Marzo & 7.4 & 1.5 & 11.2 & -0.3 & 6.2 & 5.7 & 0.9 & -0.5 & 5.1 & 1.1 \\
\hline Abril & 7.1 & 2.7 & 10.8 & 2.0 & 6.2 & 6.2 & 0.7 & -0.7 & 4.5 & 1.3 \\
\hline Mayo & 6.1 & 3.5 & 8.3 & 3.7 & 5.9 & 6.5 & 0.9 & -0.9 & 4.7 & 1.4 \\
\hline Junio & 4.9 & 3.2 & 5.0 & 3.1 & 6.6 & 6.5 & 0.4 & -0.7 & 5.0 & 1.1 \\
\hline Julio & 4.0 & 2.8 & 3.4 & 1.7 & 6.1 & 6.7 & -0.1 & -0.9 & 4.1 & 2.0 \\
\hline Agosto & 1.8 & & -1.0 & & 4.9 & & -0.1 & & 4.4 & \\
\hline Septiembre & 2.1 & & -0.6 & & 6.0 & & 0.2 & & 3.6 & \\
\hline Octubre & 1.7 & & -1.0 & & 5.5 & & 0.0 & & 3.4 & \\
\hline Noviembre & 2.2 & & -0.2 & & 6.3 & & 0.1 & & 3.0 & \\
\hline Diciembre & 1.9 & & 0.4 & & 4.7 & & 0.0 & & 2.4 & \\
\hline
\end{tabular}

Fuente: Dirección General de Estadística y Censos.

\subsection{Los salarios}

El análisis de la evolución de la inflación es estéril si no se relaciona con el poder de compra de la población. Por ello, en esta sección, se intenta establecer el vínculo entre la inflación y el poder de compra de los asalariados que devengan el salario mínimo.

El arlículo 144 del Código de Trabajo dice que el trabajador tendrá derecho a "devengar un salario mínimo que cubra suficientemente las necesidades normales de su hogar en el orden material, moral y cultural". Este artículo refleja la aspiración de que Iodos los salvadoreños alcancen una vida digna desde un punto de vista material. Para verificar si tal hecho se logra existen diferentes mecanismos. Uno sería analizar la evolución de los salarios promedios y mínimos y compararlos con las canastas de consumo mínimo y ampliada. En este sentido se buscan tres datos: los valores de las canastas básicas y ampliadas de consumo, los salarios inínimos y los salarios promedios. En el Cuadro 4 se presenta la evolución del salario mínimo desde 1988 hasta los primeros siete meses de 1998.

En un discurso, del 16 de marzo, el Presidente de la República, Armando Calderón Sol, anunció que solicitaría al Consejo Nacional del Salario Mínimo un incremento de 105 colones ( 9 por ciento) al salario mínimo vigente para el comercio, la industria y los servicios, principalmente para absorber el pago al nuevo régimen de pensiones del tres por ciento (ver Proceso, No. 801). A partir del primero de mayo del corriente año se puso en vigencia el nuevo salario inínimo, anunciado por el presidente, con el 9 por ciento de aumento. En el Cuadro 5 se presenta la evolución de los salarios mínimo nominal y real desde 1988. Desde el último incremento del salario mínimo en 1994, éste ha ido disminuyendo en términos reales hasta abril de 1998, pero, a pesar del incremento nominal, para julio de 1998 el poder de compra del salario mínimo era todavía 22.5 por ciento más bajo que en 1988.

Para recuperar el poder adquisitivo del salario mínimo para diciembre de 1988, éste habría tenido que aumentar a C54.21, es decir, tendría que haber sido del $\mathbf{4 0 . 8}$ por ciento, muy por encima del 9 por ciento decretado por el gobierno y muy por debajo del incremento de 71 por ciento sugerido por algunos diputados de oposición, en una pieza de correspondencia de la Asamblea Legislativa, fechada el 12 de mayo de 1998, y donde no se establecía ningún criterio concreto. Para tener una idea de cuál debería ser el ajuste correcto, habría que comparar el salario mínimo con la canasta básica ampliada urbana (CBAU). A finales de 1997 se esti- 
maba que el valor de dicha canasta era de $\$ 2,516.2$, lo cual sugirió que el incremento del salario mínimo debió haber sido de aproximadamente 117 por ciento, y no del 9 por ciento decretado por el gobierno. En el Cuadro 5 se muestra la canasta básica mensual de acuerdo con los datos ofi- ciales hasta 1997. Puesto que el último dato que se tiene corresponde a 1997, se utilizará éste como referencia. Esto implica que estaríamos sesgando nuestro cálculo de ajuste del salario mínimo a la baja, pues la canasta básica de consumo correspondiente a junio de 1998 debería ser más alta.

\section{Cuadro 5}

Evolución del salario mínimo

\begin{tabular}{|c|c|c|c|c|c|}
\hline Año & $\begin{array}{c}\text { Salario } \\
\text { mínimo nominal }\end{array}$ & $\begin{array}{c}\text { Aumento } \\
\text { salarial nominal }\end{array}$ & $\begin{array}{c}\text { IPC } \\
\text { Dic. } 1988\end{array}$ & $\begin{array}{c}\text { Salario } \\
\text { Real Dic/92=100 }\end{array}$ & $\begin{array}{c}\text { Indice } \\
\text { Dic/88=100 }\end{array}$ \\
\hline 1988 & $\mathrm{C} 18.00$ & & 51.52 & C34.94 & 100 \\
\hline 1989 & $\mathrm{C} 18.00$ & $0.0 \%$ & 63.61 & C28.30 & 81.0 \\
\hline 1990 & $\mathrm{C} 21.00$ & $16.7 \%$ & 75.92 & $\mathrm{C} 27.66$ & 79.2 \\
\hline 1991 & $\mathrm{C} 23.50$ & $11.9 \%$ & 83.38 & $\mathrm{C} 28.18$ & 80.7 \\
\hline 1992 & $\mathrm{C} 27.00$ & $14.9 \%$ & 100.00 & C27.00 & 77.3 \\
\hline 1993 & C 31.00 & $14.8 \%$ & 112.09 & $\mathrm{C} 27.66$ & 79.2 \\
\hline 1994 & C 35.00 & $12.9 \%$ & 122.06 & $\mathrm{C} 28.67$ & 82.1 \\
\hline 1995 & C 38.50 & $10.0 \%$ & 135.94 & C28.32 & 81.1 \\
\hline 1996 & C38.50 & $0.0 \%$ & 145.95 & C26.38 & 75.5 \\
\hline 1997 & C38.50 & $0.0 \%$ & 148.76 & C25.88 & 74.1 \\
\hline Ene-98 & C38.50 & $0.0 \%$ & 150.6 & C25.56 & 73.2 \\
\hline Feb-98 & C38.50 & $0.0 \%$ & 150.99 & C25.50 & 73.0 \\
\hline Mar-98 & C38.50 & $0.0 \%$ & 151.65 & C25.39 & 72.7 \\
\hline Abr-98 & C38.50 & $0.0 \%$ & 153.51 & C25.08 & 71.8 \\
\hline May-98 & C42.00 & $0.0 \%$ & 154.32 & C24.95 & 77.9 \\
\hline Jun-98 & $\mathrm{C} 42.00$ & $0.0 \%$ & 154.46 & C24.93 & 77.8 \\
\hline Jul-98 & C42.00 & $0.0 \%$ & 155.15 & C24.81 & 77.5 \\
\hline
\end{tabular}

Fuente: Fusades, Diario Oficial, No.72, 22 de abril, 1998 y elaboración propia.

Aquí no se está argumentando que el salario mínimo debió haberse aumentado a $\$ 2,516.2$, pues el impacto de este aumento sobre la pobreza debe estudiarse para poder tomar una decisión seria. Pero tal como se ha llevado a cabo el incremento del mes de mayo, parece que las autoridades competentes no han considerado este tipo de estudios y, más bien, la decisión ha sido bastante arbitraria.

\section{Cuadro 6}

Canasta básica ampliada (en colones)

\begin{tabular}{ccc}
\hline Años & Urbana & Rural \\
\hline 1992 & $1,779.2$ & $1,260.5$ \\
1993 & $1,955.6$ & $1,450.5$ \\
1994 & $2,096.6$ & $1,575.8$ \\
1995 & $2,166.3$ & $1,594.4$ \\
1996 & $2,459.3$ & $1,884.7$ \\
1997 & $2,516.2$ & $1,918.0$ \\
\hline
\end{tabular}

Fuente: Dirección de Información, Ministerio de Econoinía.

\subsection{Tasas de interés nominal y real}

La evolución de las tasas de interés nominal presentan ciertas características interesantes. En primer lugar, la tasa de interés nominal activa, medida por el promedio ponderado de la tasa de interés de préstamos hasta de un año plazo (TIBA) en los bancos y financieras, se muestra bastante estable de enero a abril, sin mostrar una clara tendencia a la baja como lo ha esperado el Banco Central (ver Gráfica 5). En segundo lugar, la tasa de interés nominal pasiva, medida por el promedio ponderado de las tasas de interés de depósitos a plazo de 180 días en los bancos y financieras (TIBP), muestra una clara tendencia a disminuir, de 11.5 por ciento en enero a 10.16 en abril; sin embargo, no se espera que esta tendencia continúe en los próximos meses. En tercer lugar, se observa que el diferencial de tasas de interés de enero de 1996 a abril de 1998 tendió a permanecer alrededor del 5 por ciento, a excepción del segundo semestre de 1997 que disminuyó de 4.40 por ciento en junio 
de 1997, a 2.95 por ciento en diciembre de 1997, y llegó a casi un 2 por ciento por debajo de su nivel normal. Esta caída del diferencial se debe al alza en las tasas de interés pasivas para mantener los niveles de depósitos del público, como resultado de la desconfianza en el sistema financiero a raíz de los fraudes de Finsepro en julio de 1998. Una vez superada esta desconfianza, las tasas de interés pasivas han vuelto a caer entre los meses de enero y abril, lo cual permitió que el diferencial volviera a sus niveles normales de aproximadamente 5 por ciento. Por lo tanto, si las tasas de interés activas se mantienen estables, posiblemente las tasas de interés pasivas no sigan cayendo tan rápido como en los primeros meses de 1998.

\section{Gráfica 5}

Tasas de interés activas y pasivas
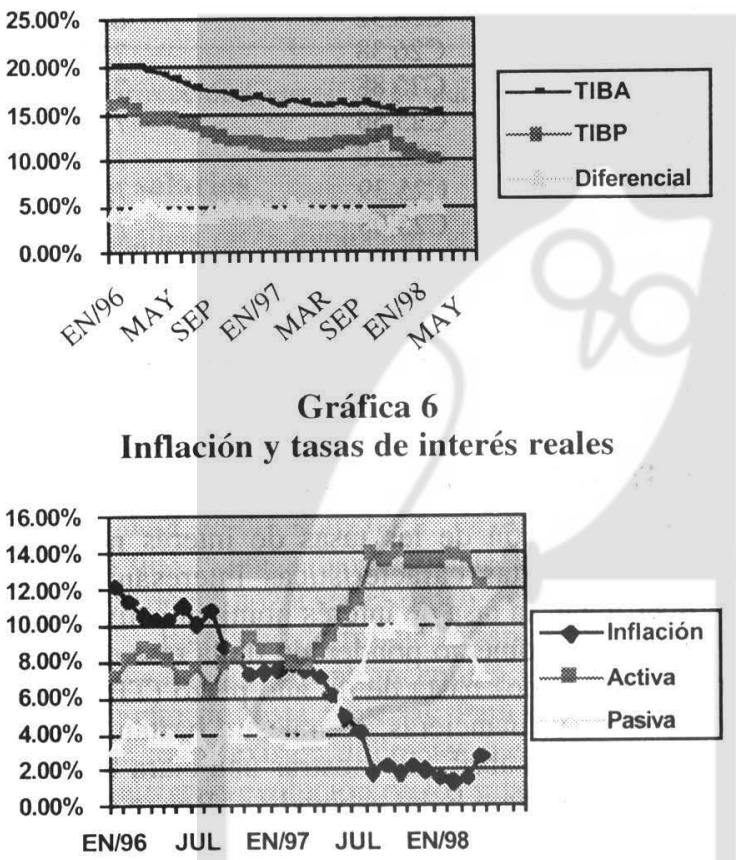

Para evaluar el comportamiento de la tasa de interés real la comparamos con la tasa de inflación -a través de una lórmula- para obtener las TIBP y la TIBA en términos reales ${ }^{4}$. Estas apare- cen en la Gráfica 6. Aquí observamos que la reducción de la inflación se refleja en el comportamiento de las tasas de interés. A medida que la inflación se redujo en 1997, las tasas de interés reales, tanto activas como pasivas, fueron aumentando paulatinamente. En los primeros meses de 1998, la tasa de interés pasiva real ha ido disminuyendo como producto de una mayor inflación y una menor tasa de interés nominal. Con respecto a la tasa de interés activa real, ésta sube levemente en febrero pero vuelve a caer en los meses de marzo y abril como consecuencia de mayores tasas de inflación. Como se señala en Rivera Campos (1998), este comportamiento de las tasas de interés real con la tasa de inflación se debe, en buena medida, a las políticas monetaria y cambiaria del Banco Central, $y$ al fuerte flujo de divisas provenientes de las remesas familiares 5 . La política monetaria trata de controlar la oferta de dinero para mantener el nivel de inflación bajo, pero a la vez el Banco Central, al tratar de mantener un tipo de cambio fijo, se enfrenta con el fuerte flujo de remesas familiares que le obliga a comprar divisas en el mercado nacional, presionando la oferta monetaria hacia el alza, lo que se refleja en un alto nivel de reservas internacionales. Así, para cumplir con su meta de inflación, el Banco Central tiene que esterilizar el incremento en las reservas internacionales, a través de operaciones de mercado abierto, con la venta de títulos valores en el sistema financiero nacional, lo que hace que las tasas de interés se mantengan elevadas.

\section{Evolución del sector financiero}

En esta sección se analizan únicamente dos aspectos del sistema financiero que se destacan recicntemente. Uno es el cambio en la composición de la cartera de los individuos, y el otro es una tendencia al aumento de la competencia en el sistema bancario.

\subsection{La liquidez}

Los hechos más relevantes en cuanto a la liquidez son el aumento moderado de la oferta monetaria, medida por M3', que de diciembre de 1997 a mayo de 1998 ha crecido 2.9 por ciento. La reduc-

4. Las tasas de interés real se calculan de la siguiente forma: $r=[(I+i)(I+p)]-I$ donde $r$ es la tasa de interés real, $i$ es la tasa de interés nominal y $p$ es la tasa de inflación.

5. Rivera Campos. Roberto. "Mal Holandés, Esterilización Monetaria y Tasa de Interés Real en El Salvador" Documento de investigación No. 1, Instituto de Economía Aplicada, agosto, 1998. 
ción considerable del numerario (efectivo) en manos del público y los depósitos a la vista, que se redujeron 7.4 por ciento y 5.3 por ciento, respectivamente, mientras que los depósitos de ahorro y los depósitos a plazo han aumentado 2.4 y 7 por ciento, respectivamente. Por ello se tiene una leve recomposición de la cartera en manos del público, es decir, que la gente ha preferido.

\section{Cuadro 7}

Indicadores de la liquidez monetaria

(saldos en millones de colones)

\begin{tabular}{lrrrrrr}
\hline Concepto & Dic-97 & Ene-98 & Feb-98 & Mar-98 & Abr-98 & May/98* \\
\hline A. Dinero y cuasidinero & & & & & & \\
M3'=B+C.1+D) & 44,773 & 44,712 & 45,064 & 46,016 & 46,121 & 46,067 \\
B. MI (Medio circulante) & 8,015 & 7,446 & 7,542 & 7,710 & 7,864 & 7,523 \\
I. Numerario & 3,228 & 3,056 & 3,052 & 3,000 & 3,105 & 2,989 \\
2. Depósitos a la vista & 4,787 & 4,390 & 4,490 & 4,710 & 4,759 & 4,534 \\
C. M2' (M1+C.1) & 39,835 & 39,816 & 40,181 & 41,039 & 41,148 & 41,081 \\
l. Ahorros/Plazo & 31,820 & 32,369 & 32,639 & 33,329 & 33,284 & 33,557 \\
l.I Depósitos de ahorro & 10,531 & 10,526 & 10,480 & 10,835 & 10,743 & 10,787 \\
I.2 Depósitos a plazo & 21,289 & 21,843 & 22,159 & 22,493 & 22,541 & 22,770 \\
D. Otras obligaciones & 4,938 & 4,897 & 4,883 & 4,976 & 4,974 & 4,986 \\
1. Moneda extranjera & 3,285 & 3,252 & 3,234 & 3,305 & 3,311 & 3,329 \\
2. Cédulas hipotecarias & 96 & 89 & 89 & 89 & 86 & 86 \\
3. Títulos valores & 1,546 & 1,548 & 1,552 & 1,562 & 1,562 & 1,564 \\
4. Otros & 11 & 8 & 8 & 20 & 14 & 7.3 \\
\hline
\end{tabular}

Fuente: Banco Central de Reserva, Cuenta Analítica del Sistema Financicro.

* Cifras preliminares.

Cuadro 8

Evolución de la liquidez en la economía (tasa de crecimiento con respecto a diciembre de 1988)

\begin{tabular}{lrrrrrr}
\hline Concepto & Dic-97 & Ene-98 & Feb-98 & Mar-98 & Abr-98 & May/98* \\
\hline A. Dinero y cuasidinero & & & & & \\
(M3'=B+C.1+D) & $-0.1 \%$ & $0.6 \%$ & $2.8 \%$ & $3.0 \%$ & $2.9 \%$ \\
B. MI (Medio circulante) & $-7.1 \%$ & $-5.9 \%$ & $-3.8 \%$ & $-1.9 \%$ & $-\mathbf{- 6 . 1 \%}$ \\
1. Numerario & $-5.3 \%$ & $-5.5 \%$ & $-7.1 \%$ & $-3.8 \%$ & $-\mathbf{7 . 4 \%}$ \\
2. Depósitos a la vista & $-8.3 \%$ & $-6.2 \%$ & $-1.6 \%$ & $-0.6 \%$ & $-5.3 \%$ \\
C. M2' (MI+C.1) & $0.0 \%$ & $0.9 \%$ & $3.0 \%$ & $3.3 \%$ & $\mathbf{3 . 1 \%}$ \\
1. Ahorros/Plazo & $1.7 \%$ & $2.6 \%$ & $4.7 \%$ & $4.6 \%$ & $5.5 \%$ \\
I.1 Depósitos de Ahorro & $0.0 \%$ & $-0.5 \%$ & $2.9 \%$ & $2.0 \%$ & $\mathbf{2 . 4 \%}$ \\
1.2 Depósitos a plazo & $2.6 \%$ & $4.1 \%$ & $5.7 \%$ & $5.9 \%$ & $7.0 \%$ \\
D. Otras obligaciones & $-0.8 \%$ & $-1.1 \%$ & $0.8 \%$ & $0.7 \%$ & $1.0 \%$ \\
1. Moneda extranjera & $-1.0 \%$ & $-1.6 \%$ & $0.6 \%$ & $0.8 \%$ & $1.3 \%$ \\
2. Cédulas hipotecarias & $-7.3 \%$ & $-7.3 \%$ & $-7.3 \%$ & $-10.4 \%$ & $-10.4 \%$ \\
3. Títulos valores & $0.1 \%$ & $0.4 \%$ & $1.0 \%$ & $1.0 \%$ & $1.2 \%$ \\
4. Otros & $-27.3 \%$ & $-27.3 \%$ & $81.8 \%$ & $\mathbf{2 7 . 3 \%}$ & $\mathbf{- 3 3 . 6 \%}$ \\
\hline
\end{tabular}

Fuente: Cálculos propios con base en el Cuadro 5.

* Cilias preliminares 
mantener menos efectivo y depósitos en cuenta corriente y más depósitos a plazo. Puede ser que el aumento de las tasas de interés real tengan algún efecto rezagado en la recomposición de la cartera, ya que el costo de oportunidad de mantener dinero en efectivo o en depósitos de cuenta corriente es mayor; sin embargo, esta hipótesis requiere de un estudio más detallado, aunque la teoría económica así lo sugeriría. También es posible que la confianza del público en el sistema bancario haya mejorado en la medida en que han superado los problemas generados por los fraudes financieros de Insepro-Finsepro en 1997.

\subsection{La competencia en la banca}

En esta sección se analiza la competencia en la industria bancaria utilizando los dos índices de concentración más comunes; y se trata de determinar, a partir de los datos de los últimos semestres, si dicha industria tiende a ser más o menos oligopólica.

Los dos índices que más se utilizan en la concentración de una industria son: el índice de la cuota de mercado de las cuatro empresas más grandes (I-4), y el índice de Herfindahl y Hirschman (IHH). Después de medir estos índices en una industria se deben aplicar criterios para determinar la estructura del mercado en la industria. A continuación, en el Cuadro 9 se muestran los criterios utilizados en este informe. Para el caso del HHI, este criterio corresponde al que se utilizó en el Departamento de Justicia de Estados Unidos para clasificar los mercados.

En el Cuadro 10 hay un resumen de la evolución de los indicadores de concentración de la industria bancaria, que se basan en el total de depósitos captados por los bancos. En las tres fechas observadas, que corresponden al final del mes de marzo de 1997, diciembre de 1997 y marzo de 1998, al compararar los datos con los criterios establecidos en el Cuadro 9 se observa que la industria bancaria está casi en el límite de ser entre una industria competitiva y una industria con competencia monopolística u oligopólica. Al ver la evolución hasta marzo de 1998, ambos índices han disminuido levemente pero todavía no está claro si esto constituye una tendencia o no, porque para diciembre de 1997 hubo una pequeña alza en los índices de concentración.

Ahora bien, estos índices adolecen de ciertas limitaciones y, por lo tanto, antes de clasificar plenamente una industria se deben de tomar en cuenta otros criterios, principalmente el grado de apertura de la industria a la competencia extranjera y las barreras a la entrada de nuevas empresas en la industria. En este aspecto, debido a la liberalización en el sistema financiero, poco a poco va aumentando la competencia de la industria bancaria en El Salvador con la entrada de inversionistas extranjeros y nuevos bancos al sistema.

Cuadro 9

Indices de concentración de una industria

\begin{tabular}{|c|c|c|c|c|}
\hline \multirow[b]{2}{*}{ Indices de concentración } & \multirow[b]{2}{*}{$\begin{array}{l}\text { Competencia } \\
\text { perfecta }\end{array}$} & \multicolumn{2}{|c|}{ Estructura de Mercado } & \multirow[b]{2}{*}{ Monopolio } \\
\hline & & $\begin{array}{l}\text { Competencia } \\
\text { monopolística }\end{array}$ & Oligopolio & \\
\hline $\begin{array}{c}\text { Cuota de mercado de las } \\
\text { cuatro empresas más grandes } \\
(\mathrm{I}-4)\end{array}$ & $\begin{array}{l}\text { menos de } 60 \\
\text { por ciento }\end{array}$ & \multicolumn{2}{|c|}{$60-90$} & $\begin{array}{c}\text { cerca del } 100 \\
\text { por ciento }\end{array}$ \\
\hline $\begin{array}{l}\text { Indice de Herfindahl-Hirschman } \\
\text { (IHH) }\end{array}$ & menos de 1,000 & $1,000-1,800$ & más de 1,800 & 10,000 \\
\hline
\end{tabular}

Nota: El índice de Herfindahl-Hirschman se calcula sumando los cuadrados de las cuotas mercado de las 50 empresas más grandes. 
Cuadro 10

Cuota de mercado de los bancos con base en el total de depósitos e índices de concentración (en porcentajes)

\begin{tabular}{rlrrr}
\hline & & Mar-97 & Dic-97 & Mar-98 \\
\hline 1 Agrícola & 23.8 & 24.3 & 24.1 \\
2 Cuscatlán & 19.5 & 19.4 & 18.6 \\
3 Salvadoreño & 12.3 & 12.2 & 12.1 \\
4 & Comercio & 8.4 & 8.9 & 8.8 \\
5 & Desarrollo & 6.9 & 7.1 & 7.3 \\
6 Credisa & 6.2 & 5.9 & 5.6 \\
7 Bancasa & 5.8 & 5.3 & 5.4 \\
8 Ahorromet & 4.4 & 5.2 & 5.5 \\
9 & Hipotecario & 4.4 & 4.1 & 3.9 \\
10 & Fomento Agrop. & 2.0 & 2.2 & 2.5 \\
11 & Multivalores & 2.2 & 1.6 & 1.5 \\
12 & Unibanco & 1.1 & 1.1 & 1.2 \\
13 & Bancorp & 1.2 & 1.1 & 1.1 \\
14 & Promerica & 0.7 & 0.6 & 0.7 \\
15 & Citibank & 0.6 & 0.6 & 0.9 \\
16 Capital & 0.4 & 0.4 & 0.7 \\
& 0.0 & 0.0 & 0.0 \\
\hline & Total & 100.0 & 100.0 & 100.0 \\
\hline I-4 & 64.0 & 64.8 & 63.6 \\
\hline IHH & $1,341.19$ & $1,361.81$ & $1,324.36$ \\
\hline
\end{tabular}

Fuente: Elaboración propia con base en la información de la Superintendencia del Sistema Financiero.

Así se tienen los casos de los bancos Citibank, el Banco Capital, que fue adquirido por un grupo financiero de Perú, la compra - de parte- de las acciones de Ahorromet por el Scotia Bank, y la conversión de la financiera Atlacatl en banco. Además se ha anunciado la entrada - a finales del año- del grupo financiero mexicano Bancrecer que planea tener su primera sucursal en diciembre de 1998, y cuya meta es abrir 15 sucursales en la capital y otras más en los principales departamentos; además de que su especialización está en el menudeo. Con esta información, se analiza que tanto Citibank como Capital y Ahorromet han aumentado su cuota de mercado. Asimismo, la conversión de la financiera Atlacatl en banco añade una empresa más a este mercado y que todavía no aparece en los datos, pero que al introducirlos ven- dría a reducir un poco más los índices de concentración. Esto viene dando una señal respecto a que la competencia en la banca salvadoreña poco a poco va siendo mayor, lo que a mediano plazo podría significar una mejora en la calidad y cantidad de servicios bancarios, tanto para las personas individuales como para las empresas.

\section{Comportamiento fiscal en los primeros me- ses de 1998}

El análisis coyuntural sobre el desempeño de las variables fiscales en los primeros meses del año, presenta ciertas dificultades dado que existen, al menos por el lado de los ingresos, estacionalidades a lo largo de los 12 meses del año; mientras que por el lado de los egresos hay un comportamiento más homogéneo, dado que la mayor parte del presupuesto se destina para el funcionamiento. Concretamente, en el presupuesto aprobado para 1998, que asciende a 16,583.3 millones de colones 6,983.1 millones de colones (42.1 por ciento) corresponden a gastos de consumo; al adicionar otros gastos corrientes, como las transferencias, que su-

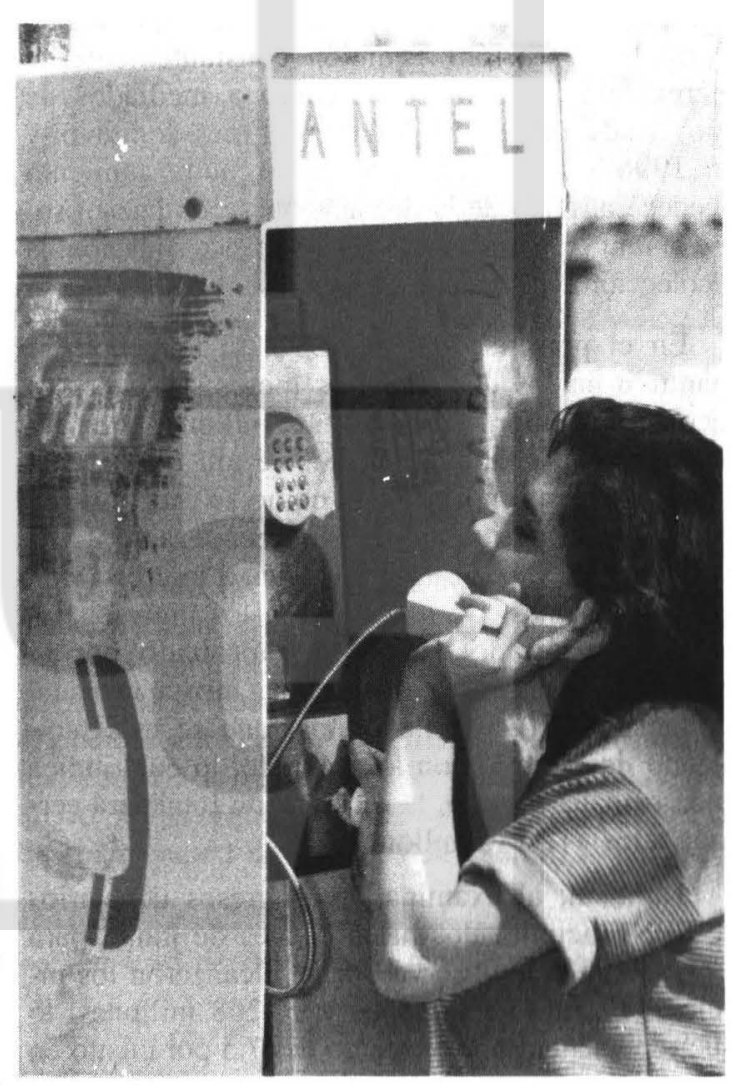


man $₫ 3,532.1$ millones ( 21.3 por ciento) y los intereses de la deuda $₫ 1,443.5$ millones ( 8.7 por ciento), resulta un total de gastos corrientes de $\not 11,958.7$ millones, que corresponden al 72.1 por ciento del presupuesto, si a ello se le adiciona el pago por amortización de la deuda que asciende a $\$ 1,363.6$ millones ( 8.2 por ciento), suma un gran porcentaje, esto es, el 80.3 por ciento del presupuesto que se reparte a lo largo de los 12 meses del año con muy pocas estacionalidades.

Si los impuestos presentan estacionalidades, los ingresos gubernamentales también presentan el mismo tipo de irregularidades, por ello, a lo largo de los doce meses de un año se presentan diversos problemas de caja, en algunos meses hay brechas sin financiar y en otros hay superávit de operación, aspecto que al final del año se consolida para indicar el monto del déficit fiscal y el déficit o superávit del presupuesto.

\subsection{Comportamiento de los impuestos}

En la Gráfica 7 se puede apreciar el aspecto de estacionalidad. De enero a febrero siempre se reduce la recolección, y en marzo se experimenta cierta recuperación. También constantemente se incrementa la recolección como a mediados de año; desde 1993 a 1995 fue en el mes de mayo, y en 1996 y 1997, en abril; este comportamiento obedece al pago de la declaración del impuesto sobre la renta que se hace. A partir de esta situación, la recolección se estabiliza en los meses siguientes.

En el presente año de 1998 , la tendencia se mantuvo en los dos primeros meses; en enero se recolectó un monto de $\notin 1,097.5$ millones y en febrero cayó a 4852.7 millones, de allí que sea un comportamiento normal. Tal como se esperaba, en marzo se experimentó cierta recuperación con \$984 millones, y en abril se alcanzó la cresta con \& 1,534 millones. De acuerdo con los ingresos tributarios esperados, según lo aprobado por la Asamblea Legislativa, tienen una media mensual simple de $₫ 1,015$ millones, así que se está recibiendo de acuerdo con lo esperado, lo cual indica que, a finales de año, la recolección total será cercana a Ios $\$ 12,180$ millones.

También, al examinar los ingresos tributarios de SPNF acumulados hasta el mes de junio, para 1997 y 1998, se observa que se alcanzaron los niveles de $45,830.6$ millones y $₫ 6,268$ millones, lo que representa un incremento del 7.5 por ciento en la recolección de impuestos del presente año. Esto revela un aspecto positivo por el esfuerzo del Ministerio de Hacienda en mejorar la recaudación, principalmente del IVA. A diciembre de 1997, sólo el IVA representaba un $\mathbf{5 4}$ por ciento de los ingresos tributarios, mientras que los impuestos sobre la renta representaban un 27 por ciento de los ingresos tributarios. Esto refleja una estructura impositiva que no favorece la equidad, dado que los primeros corresponden a la categoría de impuestos regresivos en el sentido de que, como porcentaje de su ingreso, las personas de bajos ingresos pagan una tasa mayor. Puesto que el sistema tributario actual descansa más sobre estos impuestos se puede afirmar que es un sistema regresivo.

\section{Gráfica 7}

Ingresos tributarios 1995-1998 (millones de colones)

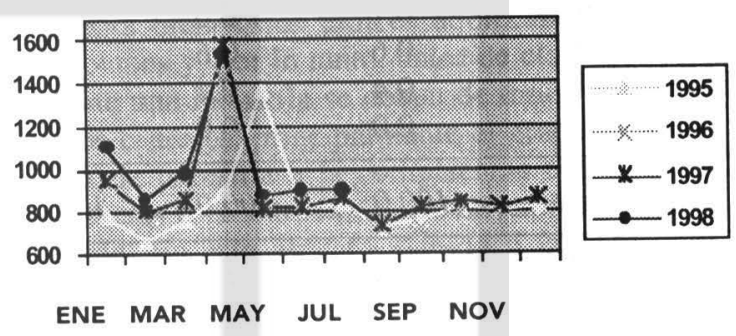

\subsection{Otros ingresos}

Respecto al comportamiento de otros ingresos, no se dispone de una serie homogénea, como en el caso de los impuestos, ya que se tiene que desde 1993 hasta 1996 se dispone del comportamiento mensual de los ingresos del Gobierno Central, y de 1997 en adelante, de los datos del Sector Público No Financiero (SPNF).

Un aspecto que se destaca es el comportamiento del superávit de las empresas públicas que ingresan al Fondo General. En 1997, en los dos primeros meses se recibieron $\$ 310$ millones por dicho concepto, mientras que en 1998, en enero y febrero, apenas fueron $₫ 51$ millones, situación que hace prever una caída drástica en dicho concepto, que se verá reflejada en una mayor presión sobre el déficit fiscal al final del año. Este comportamiento puede explicarse por el hecho de que las empresas que han sido privatizadas a lo largo del primer semestre de 1998, como las distribuidoras 
de energía eléctrica y las de telecomunicaciones, y algunas que están en proceso de privatización, como los ingenios azucareros, son empresas rentables y que, por lo tanto, las no rentables son las que continuarán en poder del Estado. Este comportamiento de parte del sector público, de deshacerse de las empresas rentables y de conservar las deficitarias, es contrario al espíritu privatizador desarrollado con la finalidad de reducir los déficit fiscales, ya que se está actuando en sentido totalmente inverso, pues, al vender las empresas rentables y conservar las deficitarias, el resultado lógico es que el déficit fiscal se incremente de manera irremediable.

A este respecto es importante mencionar lo que el Banco Interamericano de Desarrollo indica como origen del proceso privatizador en las economías de América Latina: "con el auge de las privatizaciones que se iniciaron a fines de los ochenta y se aceleraron a principios de los noventa, América Latina empezó a escribir un nuevo capítulo en su programa de reformas estructurales, revirtiendo décadas de intervención estatal. En ciertos sectores de la infraestructura, como la electricidad y el agua, en los que anteriormente el sector privado había desempeñado un rol más activo, el Estado intervino con frecuencia porque no se contaba con suficientes capitales privados para financiar las inversiones necesarias. En muchas de las empresas estatales los gastos fueron superiores a los presupuestados, y no se contaba con el mercado para disciplinar el comportamiento. En muchos casos los resultados fueron desalentadores, y muchas empresas de propiedad estatal fueron altamente ineficientes y representaron una sangría para las finanzas públicas. El Movimiento en favor de la privatización se inició y adquirió impulso, en parte, como reacción a estos problemas". En otras palabras, para el Banco Interamericano de Desarrollo, en buena medida, uno de los justificantes de la privatización radica en que el Estado debe deshacerse de las empresas no rentables para reducir el déficit fiscal.

Para el Banco Mundial, su posición al respecto se puede resumir de la siguiente forma: "Las empresas estatales improductivas a menudo constitu- yen una pesada carga para las finanzas estatales. Una solución obvia es la privatización. Lo que ocurre es que, en general, es más fácil vender los activos del Estado cuando se dan condiciones propicias para el desarrollo del sector privado"?. En el caso particular de El Salvador, lo que ha operado es precisamente ello; el sector privado, nacional o externo, ha privilegiado y/o exigido que se privaticen empresas que ya contaban con cierto nivel de rentabilidad, o que han exigido que el Estado asuma responsabilidad para ello. Este fue el caso de la banca que - previo a su privatización- fue totalmente saneada a costa del erario público; en otras palabras, en el caso de El Salvador, el proceso de privatización que se ha seguido le ha implicado un costo presupuestal, mediante gastos directos o por la vía de vender empresas rentables, mientras que las no rentables continúan en poder del Estado y, hasta donde se tiene conocimiento, no existen planes para ser privatizadas, tal es el caso de ANDA, FENADESAL y otras.

\section{Gráfica 8}

Superávit de empresas públicas (millones de colones)

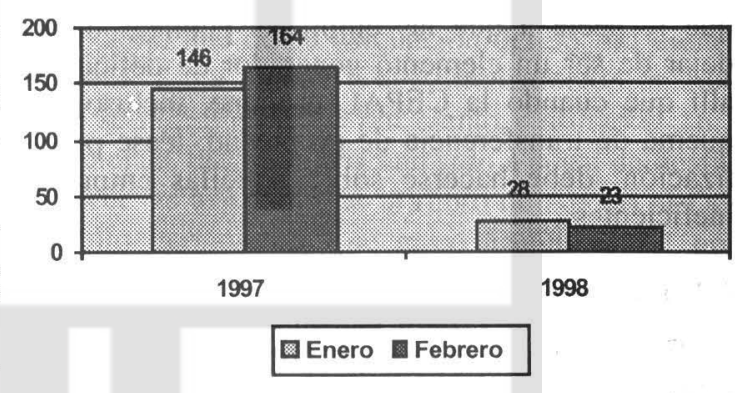

El planteamiento de la CEPAL, respecto de las empresas públicas, es que hay que realizar una "Reforma de las empresas públicas que apunte, por un lado, a la eficiente asignación de los recursos y a la ampliación de la capacidad fiscal (entre cuyas aplicaciones se encuentran las políticas más orientadas a favorecer la equidad), como resultado indirecto de la reducción del déficit público, del alivio de los requerimientos de inversión pública o de la obtención de ingresos de capital, y, por otro

6. BID, "Progreso económico y social en América Latina", informe de 1996 con el tema especial de "Cómo organizar con éxito los servicios sociales".

7. Banco Mundial "Informe sobre el desarrollo mundial". De 1997, con el tema de "El Estado en un mundo en Iransformación". 


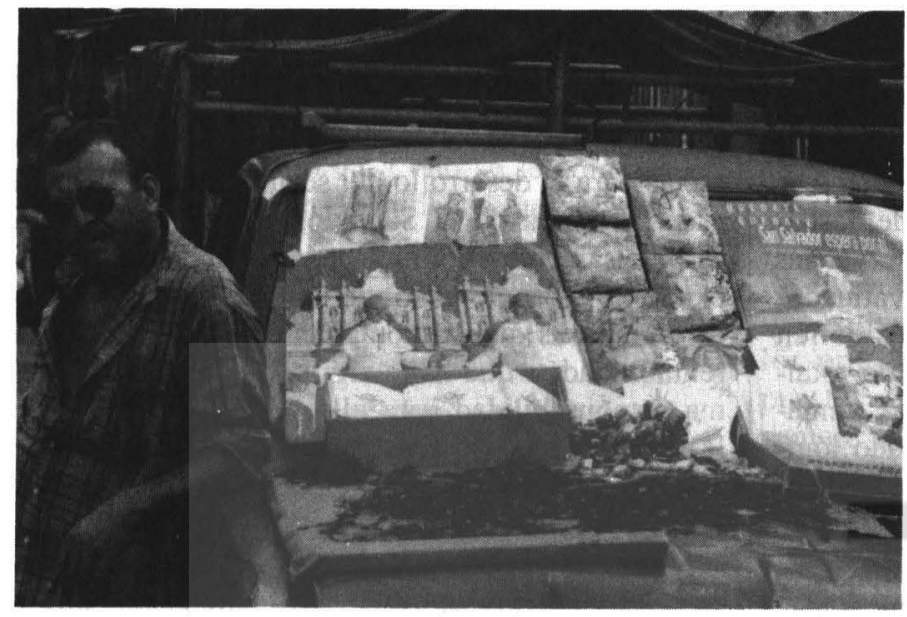

lo tanto, durante el mes de enero del presente año se tuvo que trabajar con el presupuesto de 1997, según lo establece la Constitución?. Esta situación obligó a que el gasto de enero de 1998 se realizara con prudencia, sin extralimitaciones. Una vez que se superó el impasse en la aprobación del presupuesto, en el mes de febrero, como era de esperarse, el nivel del gasto tendió a crecer, esto motivado por dos razones: una porque se estaba operando con el presupuesto del año en cuestión, y la otra, para pagar algunas transacciones realizadas en enero.

Derivado de la situación anterior, el lado, a la equidad de los esquemas de transferencia de propiedad"k. Como se desprende de la posición de la CEPAL, a las empresas públicas hay que hacerlas eficientes además de incrementar su nivel actual al respecto. En todo caso, debe ser un sector que cada vez influya menos en la determinación de los déficits públicos. En cierta medida, su planteamiento se acerca al del Banco Mundial y al del Banco Interamericano de Desarrollo, en lo que respecta a que las empresas públicas deben dejar de ser un elemento generador de déficit, de allí que cuando la CEPAL propone, incluso, esquema de transferencia de propiedad, léase privatización, debe hacerse sobre aquellas empresas ineficientes.

\subsection{Los gastos}

En cuanto al gasto, se dispone de información sobre el gasto del SPNF. En la Gráfica 8 se presenta una comparación de los meses de enero a junio, entre los años 1997 y 1998. Vemos que en enero de 1998, el nivel del gasto es inferior al del mismo mes de 1997; esta situación se explica por el hecho de que el presupuesto para 1998 no fue aprobado hasta ya bien entrado el mes de enero y publicado en el Diario Oficial del 28 de enero; por en enero de 1998 fue de $\$ 493.2$ millones, un tanto por arriba del mismo mes de 1997 que alcanzó $\$ 460.6$ millones. Al tomar en cuenta lo acontecido en febrero de 1998, lo lógico sucedió; el nivel de ahorro cayó hasta los 74.8 millones y quedó muy por abajo del de febrero de 1997, que fue de \$205.7 millones. En el mes de marzo, el ahorro del SPNF fue negativo por un monto de $\$ 123 \mathrm{mi}-$ llones, para luego experimentar un incremento sustancial en abril, por la recaudación del impuesto sobre la renta, que llegó hasta $\$ 905$ millones. En mayo hubo un pequeño aumento de $₫ 28$ millones, $y$ en junio hubo otra vez un ahorro negativo por un monto de $\$ 226$ millones. Al analizar lo acontecido durante el primer semestre de 1998 con el mismo período de 1997, el ahorro del SPNF había acumulado un total de $\notin 1,152$ millones comparado con $₫ 1,793$ millones, es decir, que el ahorro en 1998 fue inferior en $\$ 641$ millones, lo cual no es un buen augurio para lo que acontecerá en el resto del año.

\subsection{La distribución del gasto}

La distribución del gasto por áreas de gestión de acuerdo con el presupuesto aprobado para 1998, quedó de la forma siguiente:

8. CEPAL, "Equidad y transformación productiva: un enfoque integrado", Santiago de Chile, 1992.

9. El artículo 227 establece que una ley especial regulará el procedimiento que deba seguirse cuando al cierre de un ejercicio fiscal no esté aún en vigor el presupuesto del nuevo ejercicio, y de acuerdo con la Ley General de Presupuesto, en caso de que para un determinado año no se haya probado su respectivo presupuesto, se continuará funcionando de acuerdo con el presupuesto del año anterior inmediato. 


\section{Cuadro 11 \\ Distribución del presupuesto 1998}

\author{
C. Administrativa \\ A. Justicia y Seguridad \\ D. Social \\ D. Económico \\ Deuda Pública \\ O. Generales
}

Total $16,583.3$

\section{Gráfica 9}

Distribución del presupuesto por área de gestión 1988

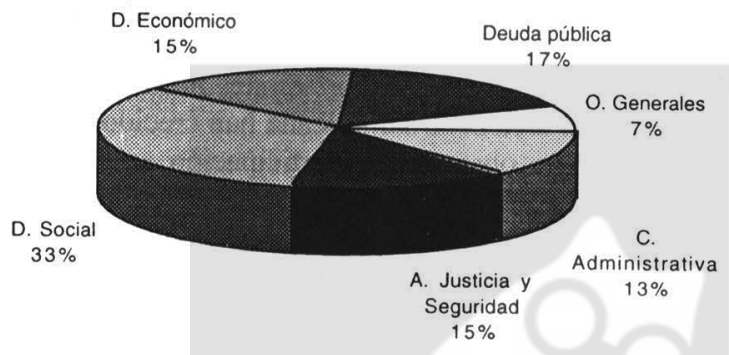

En la Grálica 9 se evidencia que la principal prioridad es el gasto en Desarrollo Social, con la tercera parte del presupuesto; le sigue la Deuda Pública con el 17 por ciento; con un 15 por ciento se encuentran dos asignaciones: la Administración de Justicia y Seguridad Ciudadana, junto con el Apoyo al Desarrollo Económico; la Conducción Administrativa recibe el 13 por ciento y, por último, las Obligaciones Generales, el 7 por ciento.
De acuerdo con el gasto efectivamente realizado durante el primer trimestre de 1998 y comparado con el mismo período de 1997, la situación se presenta en el Cuadro 12.

Se puede observar que, a nivel de la distribución del gasto por Areas de Gestión, de 1997 a 1998, se han experimentado una serie de modificaciones importantes, entre las que destacan: la reducción del monto en $₫ 12.4$ millones; las asignaciones que disminuyeron fueron Apoyo al Desarrollo Económico en $₫ 52.6$ millones, la Conducción Administrativa en $₫ 76.5$ millones y las Obligaciones Generales en $₫ 74.0$ millones. Mientras que las que se incrementaron fueron tres: Desarrollo Social, con $\notin 1,12.6$ millones; Administración de Justicia y Seguridad Ciudadana con $\$ 50.6 \mathrm{mi}-$ llones, y la Deuda Pública en $\$ 27.5$ millones.

A nivel de lo que fue la asignación aprobada por la Asamblea (ver Gráfica 9) y los resultados de lo ejecutado durante el primer trimestre de 1998, se pueden observar cambios de énfasis entre lo presupuestado y lo realizado. En primer lugar destaca el mayor énfasis en los gastos en Desarrollo Social, que de su asignación del 33 por ciento gastó 37.8 por ciento; a la Administración de Justicia se le asignó el 15 por ciento y utilizó el 16.7 por ciento. Estos énfasis han sido a costa de desfavorecer las asignaciones al rubro de Apoyo al Desarrollo Económico, que gastó apenas el 7.1 por ciento del total, cuando su presupuesto asignado fue del 15 por ciento del total. Esto significa que el gobierno de Calderón Sol continúa con su práctica de descuidar el apoyo a gastos que van directamente al desarrollo económico.

\section{Cuadro 12}

Gasto público realizado por área de gestión primer trimestre de 1997 y 1998 (en millones de colones)

\begin{tabular}{lrrrr}
\hline & 1997 & $\%$ & 1998 & $\%$ \\
\hline D. Social & $1,030.3$ & $33.9 \%$ & $1,142.9$ & $37.8 \%$ \\
A. D. Económico & 266.3 & $8.8 \%$ & 213.7 & $7.1 \%$ \\
Admón Justicia y Seguridad & 455.9 & $15.0 \%$ & 506.5 & $16.7 \%$ \\
Cond. Admiva. & 494.3 & $16.3 \%$ & 417.8 & $13.8 \%$ \\
Deuda Pública & 504.9 & $16.6 \%$ & 532.4 & $17.6 \%$ \\
Oblig. generales & 287.5 & $9.5 \%$ & 213.5 & $7.1 \%$ \\
\hline Total & $3,039,2$ & $100.0 \%$ & $3,026.8$ & $100.0 \%$ \\
\hline
\end{tabular}

Fuente: Ministerio de Hacienda. 


\section{Evolución del sector externo}

El comportamiento general del sector externo todavía es positivo. Un aspecto que se trata de destacar es que, contrario a lo que se quiere hacer pensar, la maquila no es la principal fuente de exportación del país, más bien lo siguen siendo las exportaciones de café. A continuación se analiza la evolución de las exportaciones, el déficit en la balanza comercial y los superávits de cuenta corriente y de capitales, así como su efecto en la acumulación de reservas internacionales.

\subsection{Exportaciones}

$\mathrm{Al}$ analizar las exportaciones observamos que, al mes de junio, las exportaciones totales son 7.4 por ciento mayores que el total acumulado al mes de junio de 1997. Pero en relación con las exportaciones, excluyendo la maquila, éstas son 0.4 por ciento más bajas que el año anterior. Esta discrepancia se debe a que en este año los precios internacionales del café han bajado con respecto al año anterior que fueron extraordinariamente elevados; por esa razón, las exportaciones tradicionales a junio de 1998 son más bajas que las de junio de 1997, sin embargo, son mayores que las de junio de 1996.
Gráfica 10

Exportaciones

(millones de dólares al mes de junio)

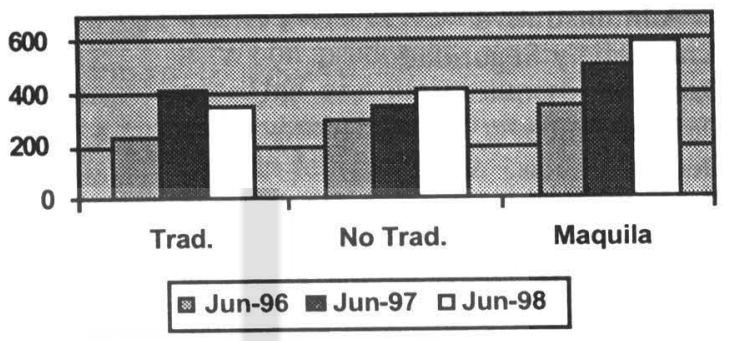

En cuanto a las exportaciones no tradicionales, éstas han crecido con respecto a las acumuladas al mes de junio del año anterior, principalmente por un mayor nivel de exportaciones no tradicionales a la región centroamericana, que han crecido un 7.4 por ciento con respecto al total acumulado a junio de 1997, mientras que las exportaciones no tradicionales fuera del área centroamericana han crecido un 32 por ciento; no obstante, su participación en el total todavía es pequeña, por lo que no tiene un impacto muy alto a nivel agregado. Así tenemos que, en conjunto, las exportaciones no tradicionales acumuladas al mes de junio han crecido 14.1 por ciento con respecto a la misma cifra del año anterior.

Cuadro 13

Estimación de las exportaciones netas de café versus las de maquila (en millones de dólares)

\begin{tabular}{|c|c|c|c|c|}
\hline & 1995 & 1996 & 1997 & jun-98* \\
\hline 1. Bienes intermedios en agricultura & 95.5 & 116.9 & 133.0 & \\
\hline 2. Bienes de capital en agricultura & 12.2 & 12.5 & 17.0 & \\
\hline 3. Total ( filas $1+2$ ) & 107.7 & 129.4 & 150.0 & \\
\hline 4. Exportaciones de café & 361.9 & 339.0 & 475.9 & 277.0 \\
\hline 5. Porcentaje sobre las export. de café (filas 3/4) & $30 \%$ & $38.2 \%$ & $32 \%$ & $33 \% * *$ \\
\hline 6. Exportaciones netas de café (filas 4 - 3) & 254.2 & 209.6 & 325.9 & 185.2 \\
\hline 7. Exportaciones netas de maquila (filas 8 -9) & 147.6 & 213.6 & 291.1 & 167.0 \\
\hline 8. Exportaciones de maquila & 646.6 & 764.9 & 1056.8 & 592.0 \\
\hline 9. Importaciones de maquila & 499.0 & 551.3 & 765.7 & 425.0 \\
\hline
\end{tabular}

Fuente: Elaboración propia con base en datos del BCR.

* Cifras preliminares.

** Se calcula como el promedio 1995-1997. 
Las exportaciones de maquila siguen presentando el mismo dinamismo de los años anteriores ya que, a junio de 1998, éstas eran un 19.4 por ciento mayor que la misma cifra a junio de 1997. Sin embargo, hay que reconsiderar este crecimiento positivo en las exportaciones de maquila, pues su nivel de generación de valor agregado y de divisas no es tan alto como se quiere hacer pensar ${ }^{10}$. En una aproximación le podemos restar a las exportaciones de maquila las importaciones que éstas realizan, y evaluar el crecimiento de las exportaciones netas de maquilas. Esto lo podemos comparar con una estimación de las exportaciones netas de café, tal como se muestra en el Cuadro 13. En este cuadro se observa que en todos los períodos, a excepción de 1996, el café es el principal generador de divisas en El Salvador y no la maquila. No obstante, de seguir las tendencias recientes, eventualmente la maquila se convertirá en la principal generadora de divisas del país, como sucedió en 1996 cuando los precios del café bajaron.

\section{Gráfica 11}

\section{Reservas Internacionales Netas} (millones de dólares)

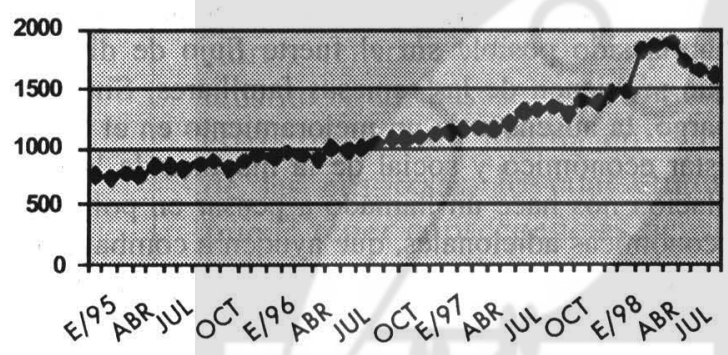

\subsection{Balanza comercial}

Al restar las importaciones de las exportaciones de bienes y servicios, se obtiene el saldo en la balanza comercial. De acuerdo con los datos acumulados hasta el mes de junio de 1998, en compa- ración con cifras equivalentes para los años 19951997, existe una tendencia a reducir el déficit en la balanza comercial (ver Gráfica 12 ).

\section{Gráfica 12}

Balanza comercial de bienes (millones de dólares al mes de junio)

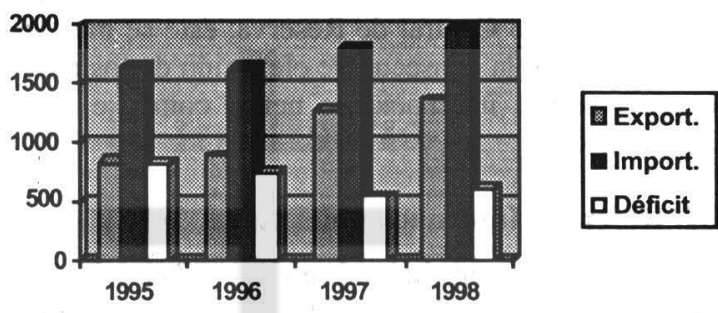

Lo relevante este año es que, en relación con 1997, existe un leve incremento en el déficit de la balanza comercial debido a la reducción en los precios del café en comparación con el año anterior, pero es positivo al compararlo con los dos años anteriores (1995-1996); el déficit comercial es menor en términos absolutos. Es más, al comparar el déficit de este período con los correspondientes datos de los años 1995-1997, se observa, por ejemplo, que en relación con las exportaciones al mes de junio, el déficit ha pasado de representar un 97 por ciento del valor de las exportaciones a un 45 por ciento en el corriente año. Mientras que respecto a las importaciones, el déficit en la balanza comercial ha bajado de un 49 por ciento a junio de 1995 , a un 31 por ciento a junio de 1998.

\subsection{Balanza de cuenta corriente}

Como viene sucediendo año con año, el déficit comercial es cubierto, en gran parte o a veces totalmente, por el flujo de remesas de familiares de salvadoreños que viven en Estados Unidos. Así tenemos que para junio de 1998, el saldo acumulado en la balanza de cuenta corriente es positivo, ya que sólo el flujo de remesas familiares es mayor que el

10. Para hacer una comparación exacta necesitaríamos las importaciones del sector café para cada perlodo, tal y como se informa para la maquila, pero estos datos no se reportan periódicamente. Para compensar la carencia de datos, hacemos estimaciones de las importaciones del sector café, sumando las importaciones de bienes intermedios y de capital del sector agropecuario. Obviamente dicho procedimiento subestima las exportaciones netas del café. pero dado que queremos probar que el café todavía constituye la principal fuente de divisas por exportaciones. decidimos adoptar este procedimiento que actúa en contra de nuestra hipótesis. De esta forma no se puede argumentar que sesgamos nuestros estimados, lo cual robustece nuestras conclusiones. 
saldo negativo de la balanza comercial, 616 millones de dólares a junio de 1988. Más aún, en el primer semestre de este año se tiene un saldo positivo en la balanza de capitales, por lo que el saldo global de la balanza de pagos arrojó un cifra positiva de 185 millones de dólares, lo cual debería ejercer una presión sobre el tipo de cambio a la baja, pero, debido a la política de tipo de cambio fijo que implementa el Banco Central de Reserva, éste se mantiene estable, con la consecuente elevación de los niveles de reservas internaciones netas, como se ve a continuación.

\subsection{Reservas Internacionales Netas (RIN)}

En relación con diciembre de 1997, las Reservas Internacionales Netas (RIN) se han incrementado en 141 millones de dólares, lo que confirma que para mantener un tipo de cambio fijo, el Banco Central se ve forzado a comprar dólares.

Además de este incremento a lo largo del primer semestre de 1998, se observa un incremento considerable en las RIN, desde el mes de enero hasta abril, principalmente por el incremento de depósitos en el exterior. Mientras que la reducción de las Reservas Internacionales Netas, en los últimos tres meses, se debe a la cancelación de la deuda externa por parte del sector público, principalmente del gobierno central, y en menor medida por las empresas autónomas.

\section{Conclusión}

El presente informe de corto plazo refleja que en la economía salvadoreña hay una serie de factores positivos, desde un punto de vista macroeconómico, como un crecimiento económico moderado, una tasa de inflación baja en relación con otros países, una solvencia externa favorable, dado el alto nivel de reservas internacionales, la evolución rápida de las exportaciones no tradicionales y otros más. Pero, desde el punto de vista del bienestar económico de la población, los resultados no son compatibles con el comportamiento macroeconómico, sino que, en varios aspectos, la economía muestra señales de desigualdad que expresan que los beneficios del crecimiento no alcanzan a llegar a la mayoría de la población. Tenemos el estancamiento del sector agropecuario, la caída del poder de compra de los trabajadores que devengan el salario mínimo, una estructura impositiva regresiva y una desigual distribución del ingreso. Se podrían mencionar más factores, pero no corresponden al presente análisis de coyuntura. Por el momento, basta hacer notar la incongruencia que existe entre la estabilidad y el crecimiento económico y la mejoría en el bienestar general de toda la población. El crecimiento y la estabilidad de la economía han sido un logro de la política económica, pero un logro —que además es preciso conservar- que no habría sido posible sin el fuerte flujo de divisas que provienen de las remesas familiares. Sin embargo, la ausencia de un mejoramiento en el bienestar económico y social de la mayoría de la población nos hace un llamado a pensar en políticas económicas adicionales, que ayuden a combatir de manera más efectiva el fenómeno de la pobreza. 